07

\title{
Влияние гамма-излучения малых доз на электрофизические свойства мезопористого кремния
}

\author{
() Д.И. Биленко, В.В. Галушка, Э.А. Жаркова, В.И. Сидоров, \\ Д.В. Терин, Е.И. Хасина
}

Саратовский государственный университет, им. Н.Г. Чернышевского E-mail: lab32@mail.ru

Поступило в Редакцию 14 июля 2016 г.

Исследовано влияние гамма-излучения малых экспозиционных доз (5-40 kR) на электрические характеристики структур на основе слоя мезопористого кремния (SiMP). Показано, что в структуре $\mathrm{Al} / \mathrm{SiMP} / p-\mathrm{Si} / \mathrm{Al}$ воздействие гаммаквантов приводит к возрастанию проводимости слоя SiMP, смещению уровня Ферми, изменению концентрации ловушек. Обнаружена долговременная память стабильного переключенного состояния в области гистерезиса $I-V$-характеристики, управляемая дозой излучения.

DOI: 10.21883/PJTF.2017.03.44228.16408

Изучение воздействия гамма-излучения на свойства кристаллических материалов (сплавов и полупроводников) показало, что существует так называемый эффект малых доз $\left(D=10^{3}-10^{5} \mathrm{R}\right)$, при котором в отличие от больших доз происходит упорядочение структуры и соответственно улучшение электрофизических свойств материала. В частности, уменьшение дефектов в кристалле приводит к повышению проводимости [1], увеличению времени жизни неосновных носителей заряда в облученных кремниевых диодных структурах [2]. Исследования влияния гамма-излучения на свойства пористого кремния (PSi) были направлены в основном на изучение радиационной стойкости, выяснение природы фотолюминесценции (ФЛ) пористого кремния и зависимости последней от интенсивности облучения [3]. На основании измерений рамановского рассеяния и люминесценции при радиационном воздействии ионов $\mathrm{Ar}^{+}$ был сделан вывод о радиационной стойкости пористого кремния по сравнению с монокристаллическим $\mathrm{Si}$, что связано, видимо, с развитой поверхностью PSi и возможностью стока и аннигиляции дефектов. 


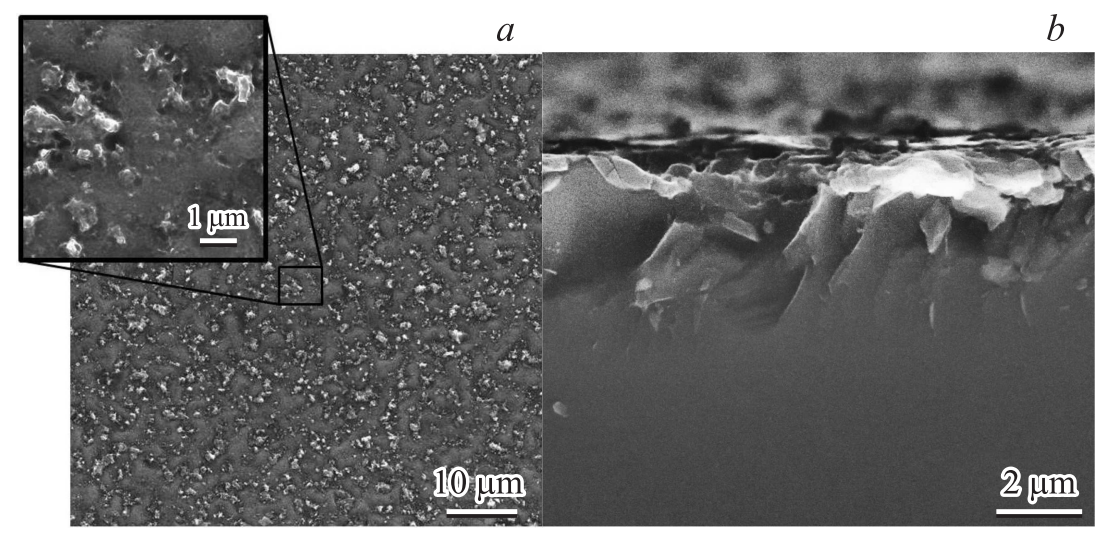

Рис. 1. Морфология поверхности структуры $\mathrm{Al} / \mathrm{SiMP} / p$-Si/Al после гамма-облучения. Экспозиционная доза $D=20 \mathrm{kR}: a-$ поверхность образца, $b-$ скол.

В работе [4] описан эффект влияния гамма-радиации на структуру пористого кремния, который выражается в уменьшении пористости. Однако влияние гамма-излучения малой интенсивности на электрофизические свойства пористого кремния практически не изучалось. Кроме того, все исследования проводились на пористом кремнии, полученном электрохимическим путем, т.е. на нанопористом кремнии, в то время как насыщение PSi различными веществами $(\mathrm{Fe}, \mathrm{Ag})$ и лекарствами возможно в случае использования мезопористого кремния (SiMP), полученного химическим травлением с использованием металлов $[5,6]$.

Целью настоящей работы являются исследования влияния гаммаизлучения на свойства SiMP для выяснения возможности управления дефектностью в материале с высоким уровнем оборванных связей, каким является пористый кремний, и рассмотрение возможности создания на основе SiMP устройств с зарядовой связью.

Мезопористые слои кремния получены на подложках $p$-типа с удельным сопротивлением $4.5 \Omega \cdot \mathrm{cm}$ в водном растворе $\mathrm{AgNO}_{3}$ с концентрацией $0.02 \mathrm{~mol}$ и плавиковой кислоты концентрацией $5 \mathrm{~mol}$ при температуре $20^{\circ} \mathrm{C}$ в течение часа [5]. Часть поверхности подложек оставалась защищенной от влияния раствора. Для удаления дендритного нароста серебра образцы были протравлены в концентрированной

Письма в ЖТФ, 2017, том 43, вып. 3 


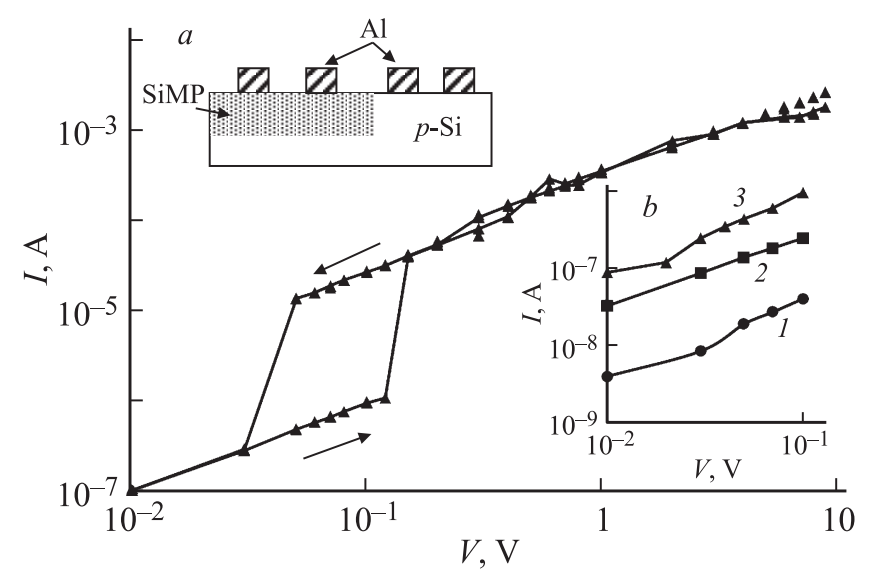

Рис. 2. Вольт-амперная характеристика структуры после гамма-излучения $D=20 \mathrm{kR}$, смещение - плюс на подложке. На вставках: $a$ - схема образца, $b-$ омический участок ВАХ при $D, \mathrm{kR}: 1-0,2-5,3-20$.

азотной кислоте в течение одного часа. Отсутствие серебра было подтверждено данными элементного анализа растровой микроскопии. Контакты в виде полосок Al на слой и подложку наносились при $t \sim 120^{\circ} \mathrm{C}$ напылением в вакууме порядка $10^{-5} \mathrm{~mm} \mathrm{Hg}$, причем контакты на подложке создавались до получения пористого слоя, поэтому проводилось вжигание при $400^{\circ} \mathrm{C}$ в вакууме в течение $40 \mathrm{~min}$ для получения омического контакта. Для облучения полученных структур применялся пучок гамма-квантов тормозного излучения бетатрона Саратовского государственного университета при максимальной энергии $E_{\gamma \max }=25 \mathrm{MeV}$. Экспозиционная доза $D$ менялась от 5 до $40 \mathrm{kR}$. Морфология и толщины слоев определялись на аналитическом комплексе на базе MIRA 2 LMU. Пример морфологии слоя SiMP после гаммаоблучения приведен на рис. 1. При используемом технологическом режиме исходные слои до облучения имели столбчатую структуру, аналогичную приведенной в [6] для образца, полученного по такой же технологии. Пористость мезопористых слоев до облучения, определенная гравиметрическим методом, составляла 0.5-0.7 при диаметре „столбов“" 100-200 nm. При облучении проявляются более крупные образования кремния размером до $600 \mathrm{~nm}$, что приводит к уменьшению

Письма в ЖТФ, 2017, том 43, вып. 3 
пористости (рис. $1, b)$. Это согласуется с данными работы по изучению влияния гамма-излучения на структуру пористого кремния, полученного электрохимическим путем [4].

Измерение вольт-амперных характеристик проводилось от источника постоянного тока при ступенчатом изменении напряжения с шагом $0.01 \mathrm{~V}$. Схема образца приведена на вставке $a$ рис. 2. ВАХ измерялись в режиме нарастания и последующего снижения напряжения. До облучения исследуемые структуры $\mathrm{Al} / \mathrm{SiMP} / p$-Si/Al имели $\mathrm{BAX}$ двух видов: барьерного типа и ВAX с токами, ограниченными пространственным зарядом (ТОПЗ) [7].

Проведенные исследования влияния гамма-излучения на электрофизические свойства мезопористого кремния показали следующее. Вид $\mathrm{BAX}$ структуры $\mathrm{Al} / \mathrm{SiMP} / p$-Si/Al типа ТОПЗ сохраняется при облучении малыми дозами. В случае структуры барьерного типа при гаммаоблучении происходит изменение вида ВАХ по мере увеличения экспозиционной дозы. Уменьшается барьер в контакте Al-SiMP. Величина барьера $\varphi_{\beta n}$ определяется, согласно [8], по формуле

$$
\phi_{b m}=\frac{k T}{q} \ln \left(\frac{A^{* *} T^{2}}{I_{s}}\right),
$$

где $A^{* *}$ при комнатной температуре $300 \mathrm{~K}$ равна $120 \mathrm{~A} \cdot \mathrm{cm}^{-2} \cdot \mathrm{K}^{-2}$, $I_{s}-$ плотность тока насыщения. При облучении $I_{s}$ возрастает, что, видимо, связано с уменьшением ловушек в обедненном слое на границе Al-SiMP. Соответственно уменьшается барьер $\phi_{b m}$. Так, при облучении с $D \sim 5 \mathrm{kR}$ величина $\phi_{b m}$ снижается от 0.67 в исходном состоянии до $0.6 \mathrm{~V}$ в облученном. По мере роста облучения свыше $10 \mathrm{kR}$ BAX имеет вид токов, ограниченных пространственным зарядом (рис. 2).

Слои SiMP после облучения становятся более низкоомными. Проводимость слоя, оцененная по омическому участку ВАХ, возрастает от $5 \cdot 10^{-7} \Omega^{-1} \cdot \mathrm{cm}^{-1}$ в исходном до $\sim 10^{-5} \Omega^{-1} \cdot \mathrm{cm}^{-1}$ после облучения с $D \sim 20 \mathrm{kR}$ (вставка $b$ рис. 2).

$\mathrm{B}$ зависимости BAX, измеренной в режиме нарастания и последующего снижения напряжения, в области ловушечного переноса носителей заряда возникает гистерезис, который обладает высокой стабильностью. При дозе облучения $\sim 20 \mathrm{kR}$ гистерезис наблюдается в диапазоне напряжений $0.05-0.2 \mathrm{~V}$ и характеризуется ростом тока в $20-30$ раз.

Стабильность значений тока в гистерезисе получена при достижении $I \sim 1 \mathrm{~mA}$ с ростом напряжения, при котором происходит практически 
полное заполнение ловушек захваченными неравновесными носителями заряда, в основном электронами, так как сечение захвата электронов намного больше сечения захвата дырок. Стабильное значение тока в гистерезисе сохраняется с высокой степенью точности до долей микроампер при последовательном многократном включении и выключении напряжения в течение $\sim 60$ суток. Затем ток постепенно уменьшается, окончательная стабилизация гистерезиса происходит через 70-90 суток, что вероятно связано с постепенным распределением накопленной энергии в кристалле при облучении [1].

Исходные значения тока достигаются при уменьшении напряжения до $V \sim 10-20 \mathrm{mV}$, что соответствует переходу от ловушечного переноса носителей заряда к омическому участку ВАХ (рис. 2). В случае структур, имеющих ВАХ с ТОПЗ и гистерезис в ВАХ до облучения, после облучения наблюдается его сужение как по шкале напряжения, так и по величине тока, что свидетельствует об уменьшении концентрации ловушек.

Концентрация ловушек рассчитывалась в области ТОПЗ двумя методами: step by step при экспоненциальном распределении ловушек по запрещенной зоне и по критическому значению напряжения $V_{n}-$ перехода от ловушечного переноса носителей заряда к квадратичной зависимости $I \sim V_{2}$ :

$$
N_{t}=\frac{\varepsilon^{\prime} \varepsilon_{0} V_{n}}{q d^{3}}
$$

где $d$ - толщина слоя, $\varepsilon^{\prime}-$ диэлектрическая проницаемость SiMP. Величина $N_{t}$ ловушек при облучении $D \sim 20 \mathrm{kR}$ падает по сравнению с исходной от $2 \cdot 10^{15}$ до $4 \cdot 10^{14} \mathrm{~cm}^{-3} \cdot \mathrm{eV}^{-1}$, при этом участок с ТОПЗ в облученных образцах смещен по шкале напряжений в область меньших V. Резкий рост тока указывает на уменьшение концентрации ловушек. Заполнение ловушек облученного слоя SiMP неравновесными носителями приводит к сдвигу положения уровня Ферми. $\Delta E_{\mathrm{F}}$ рассчитывался как

$$
\Delta E_{\mathrm{F}}=k T \ln \left(I_{2} V_{1} / I_{1} V_{2}\right),
$$

где $I_{1}, I_{2}$ и $V_{1}, V_{2}$ - значения тока и напряжения в области ТОПЗ. Сдвиг уровня Ферми обусловлен ростом концентрации свободных носителей заряда, которая изменяется в $\sim e^{3}$, при полученном сдвиге $\Delta E_{\mathrm{F}}-3 k T$, что согласуется с изменением тока в 10-20 раз.

Следует отметить, что в слоях с ТОПЗ до облучения изменение тока в гистерезисе не превышало 2-3 раза, что соответствует сдвигу

Письма в ЖТФ, 2017, том 43, вып. 3 


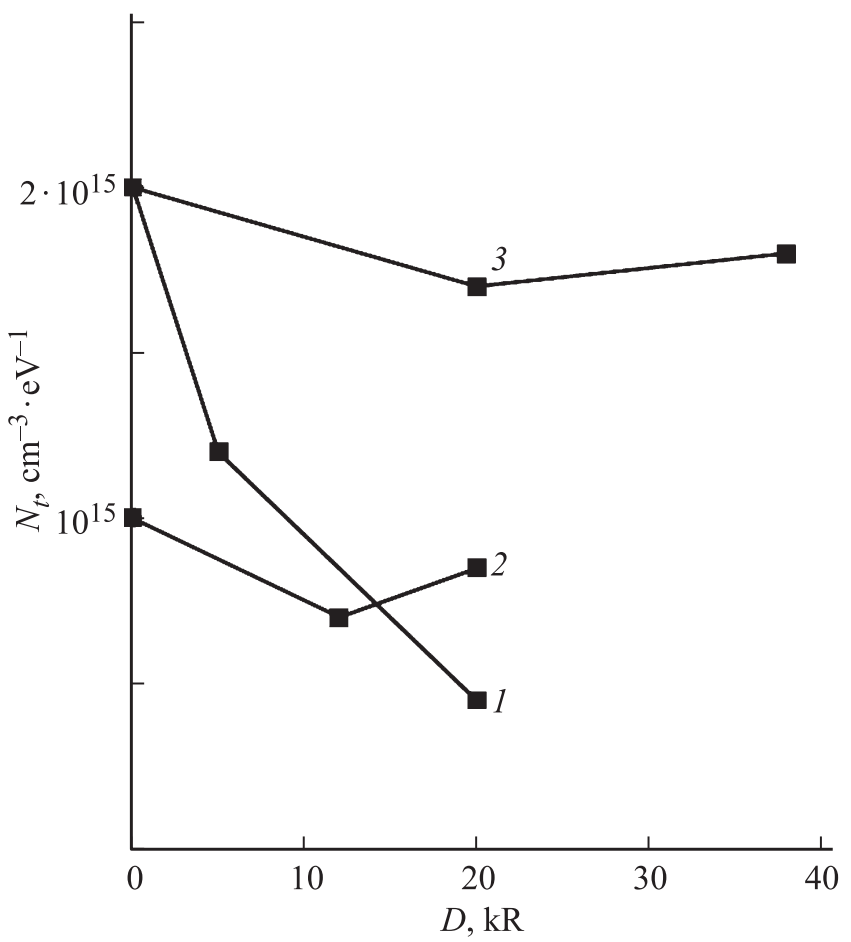

Рис. 3. Концентрация ловушек в облученных структурах $\mathrm{Al} / \mathrm{SiMP} / p$-Si/Al c ТОП3. Толщина слоя $\mathrm{SiMP}, \mu \mathrm{m}: 1-2.5,2-1,3-$ облученная подложка.

$\Delta E_{\mathrm{F}} \sim k T$. Полученное стабильное значение тока в гистерезисе свидетельствует о равновесном состоянии, при котором скорости захвата и возбуждения электронов с ловушек равны. При этом уровень Ферми сдвинут в новое стабильное положение.

Изменение концентрации ловушек в слоях пористого кремния, вызванное воздействием ионизирующего гамма-излучения зависит от свойств слоя, его толщины, вида ВАХ, влияния контактных областей. Так, например, при мощности излучения 5-20 kR концентрация ловушек в пористом кремнии падает от $2 \cdot 10^{15}$ до $4 \cdot 10^{14} \mathrm{~cm}^{-3} \cdot \mathrm{eV}^{-1}$, a влияние излучения указанной мощности на подложку практически не наблюдается (рис. 3).

Письма в ЖТФ, 2017, том 43, вып. 3 
Таким образом, показано, что малые дозы гамма-облучения снижают дефектность мезопористого кремния, повышают его стабильность и создают возможность управления зарядовыми состояниями с долговременной памятью переключенного состояния. Необходимы дальнейшие исследования для выяснения механизма временного управления этими процессами.

Авторы благодарны И.Б. Мысенко за помощь в получении образцов. Работа подготовлена в рамках базовой части государственного задания Министерства образования и науки РФ (проект № 3468).

\section{Список литературы}

[1] Мамонтов А.П., Чернов И.П. Эффект малых доз ионизирующего излучения. Томск: Дельтаплан, 2009. 286 с.

[2] Рахматов А.З., Ташметов М.Ю., Сандлер Л.С. // Вопросы атомной науки и техники. 2011. № 4. С. 26.

[3] Астрова Е.В., Витман Р.Ф., Емщев В.В. и др. // ФТП. 1996. Т. 30. В. 3. С. 507.

[4] Abbas J.K., Najam L.A., AuobSulaiman A.U. // Int. J. Physics. 2015. V. 3. N 1. P. 1.

[5] Биленко Д.И., Галушка В.В., Жаркова Э.А. и др. // ФТП. 2014. Т. 48. С. 1405.

[6] Биленко Д.И., Галушка В.В., Жаркова Э.А. и др. // Письма в ЖТФ. 2015. T. 41. B. 21. C. 80.

[7] Ламперт М., Марк П. Инжекционные токи в твердых телах. М.: Мир, 1973. $416 \mathrm{c}$.

[8] Зи С. Физика полупроводниковых приборов. Т. 1. М.: Мир, 1984. 455 с.

Письма в ЖТФ, 2017, том 43, вып. 3 